\title{
Evidence for the Immunosuppressive Potential of Calcineurin Inhibitor-Sparing Regimens in Liver Transplant Recipients with Impaired Renal Function
}

\author{
Kentaro Ide, Yuka Tanaka, Takashi Onoe, Masataka Banshodani, Hirofumi Tazawa, \\ Yuka Igarashi, Nabin Bahadur Basnet, Marlen Doskali, Hirotaka Tashiro, and Hideki Ohdan
}

Division of Frontier Medical Science, Department of Surgery, Programs for Biomedical Research,

Graduate School of Biomedical Sciences, Hiroshima University, 1-2-3 Kasumi Minami-ku, Hiroshima 734-8551, Japan

Correspondence should be addressed to Hideki Ohdan, hohdan@hiroshima-u.ac.jp

Received 14 March 2011; Accepted 9 May 2011

Academic Editor: P. Burra

Copyright ( $) 2011$ Kentaro Ide et al. This is an open access article distributed under the Creative Commons Attribution License, which permits unrestricted use, distribution, and reproduction in any medium, provided the original work is properly cited.

\begin{abstract}
Patients requiring liver transplantation (LT) frequently experience renal insufficiency (RI), which affects their survival. Although calcineurin inhibitor-sparing immunosuppressive regimens (CSRs) are well known to prevent RI, the immune state in recipients receiving CSR remains to be intensively investigated. Among 60 cases of living-donor LT at our institute, $68 \%$ of the patients had none to mild RI (non-RI group) and 32\% of the patients had moderate to severe RI (RI group). The RI group received a CSR comprising reduced dose of tacrolimus, methylprednisolone, and mycophenolate mofetil, while the non-RI group received a regimen comprising conventional dose of tacrolimus and methylprednisolone. One year after LT, the mean estimated glomerular filtration rate (eGFR) in the RI group had significantly improved, although it was still lower than that of the non-RI group. Serial mixed lymphocyte reaction assays revealed that antidonor T-cell responses were adequately suppressed in both groups. Thus, we provide evidence that CSR leads to improvement of eGFR after LT in patients with RI, while maintaining an appropriate immunosuppressive state.
\end{abstract}

\section{Introduction}

Renal insufficiency (RI) has been widely recognized as a serious complication of liver transplantation that significantly compromises patient outcome [1-4]. Since a number of patients already have varying degrees of RI, including hepatorenal syndrome, before undergoing liver transplantation, and since postoperative standard immunosuppression protocols based on calcineurin inhibitors (CNIs) can lead to severe tubular atrophy, interstitial fibrosis, and focal hyalinosis of the small renal arteries and arterioles, a majority of liver recipients develop some degree of RI [5-7]. An analysis of data from the Scientific Registry of Transplant Recipients indicates that the cumulative incidence of stage 4 [estimated glomerular filtration rate $\left.(\mathrm{eGFR})<30 \mathrm{~mL} / \mathrm{min} / 1.73 \mathrm{~m}^{2}\right]$ or stage 5 chronic kidney disease $\left(e G F R<15 \mathrm{~mL} / \mathrm{min} / 1.73 \mathrm{~m}^{2}\right.$ or need for renal replacement therapy) after liver transplantation is $18 \%$ at 5 years [8].
Late renal failure is associated with both pre- and posttransplant factors, including higher concentrations of CNIs both early and late posttransplant and can be predicted by creatinine levels in the first year posttransplant [9, 10]. The recognition of these effects induced interest in strategies using a CNI-sparing immunosuppressive regimen (CSR). Current strategies to overcome CNI toxicity include reduction or withdrawal of CNIs concurrent with switching over to less nephrotoxic drugs like the mammalian target of rapamycin (mTOR) inhibitor or mycophenolate mofetil (MMF) [11-17]. Although these strategies have clearly demonstrated the ability to reduce the incidence of nephrotoxicity in various studies, CSR may result in an increased risk for acute rejection episodes in a subset of patients.

In the present study, we investigated the immune state in liver transplant patients suffering from RI who received a CSR comprising a reduced dose of CNI, methylprednisolone, and MMF. For monitoring the immune-state response to 
antidonor allostimulation in these patients, we employed a mixed lymphocyte reaction (MLR) assay using an intracellular carboxyfluorescein diacetate succinimidyl ester (CFSE)labeling technique. By applying the CFSE-based method, the proliferation of viable $\mathrm{CD} 4^{+}$and $\mathrm{CD} 8^{+}$responder T-cells in response to allostimulation could be separately quantified using multiparameter flow cytometry [18]. The technique allowed us to find that antidonor T-cell responses were adequately suppressed in patients with RI who received the CSR and in patients without RI who received a conventional immunosuppressive regimen.

\section{Patients and Methods}

2.1. Patients. Between January 2003 and December 2009, 122 patients underwent living-donor LTs at Hiroshima University Hospital. Of these, 50 patients infected with hepatitis $\mathrm{C}$ virus (HCV) and 12 patients who received liver allografts from ABO-blood group incompatible donors were excluded from the study, because they were treated with the diverse immunosuppressive protocols. For the remaining 60 patients, the relationship between RI prior to LT and the clinical/immunological state after LT was investigated. The following information was collected at the time of the transplant: age, sex, etiology of liver disease, model for end-stage liver disease (MELD) score, and diagnosis of hepatocellular carcinoma (HCC) prior to LT. Renal function was evaluated in each participant by determining eGFR. The eGFR of each participant was calculated from their serum creatinine value ( $\mathrm{SCr}$ ) and their age by using the new Japanese equation [19] as follows:

$$
\begin{aligned}
\operatorname{eGFR}\left(\mathrm{mL} / \mathrm{min} / 1.73 \mathrm{~m}^{2}\right) \\
=194 \times \text { Age }-0.287 \\
\quad \times \mathrm{S}-\mathrm{Cr}-1.094(\text { if female } \times 0.739) .
\end{aligned}
$$

In this study, RI was defined as none to mild (eGFR $\geq$ $\left.60 \mathrm{~mL} / \mathrm{min} / 1.73 \mathrm{~m}^{2}\right)$ and moderate $\left(30-59 \mathrm{~mL} / \mathrm{min} / 1.73 \mathrm{~m}^{2}\right)$ to severe $\left(<30 \mathrm{~mL} / \mathrm{min} / 1.73 \mathrm{~m}^{2}\right)$. The MELD score was calculated for each patient using the United Network for Organ Sharing (UNOS) formula based on the laboratory values obtained just prior to LT. Patients were monitored for renal function using serum creatinine level and eGFR at 1, 3, 6, and 12 months after LT.

2.2. Immunosuppressive Protocol. The basic immunosuppressive regimen after LT for the non-RI group comprised tacrolimus (TAC) and methylprednisolone, with gradual tapering of doses. Patients with RI received a CSR comprising a reduced dose of TAC, methylprednisolone, and MMF (Figure 1). In the conventional regimen, the trough whole blood levels of TAC were maintained between 8 and $15 \mathrm{ng} / \mathrm{mL}$ in the first few postoperative weeks and between 5 and $10 \mathrm{ng} / \mathrm{mL}$ thereafter. In the CSR, the trough whole blood levels of TAC were maintained between 5 and $10 \mathrm{ng} / \mathrm{mL}$ in the first few postoperative weeks and between 3 and $5 \mathrm{ng} / \mathrm{mL}$ thereafter.

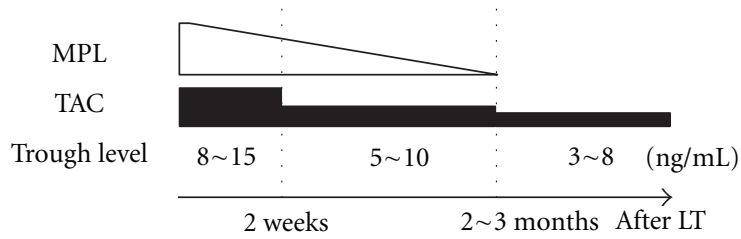

(a) Conventional regimen

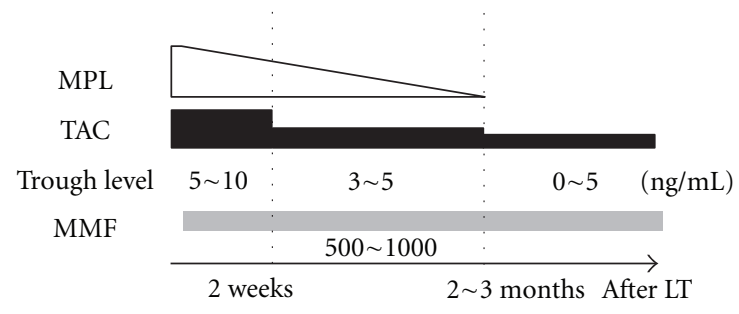

(b) CNI-sparing immunosuppressive regimen

FIgURE 1: Immunosuppressive protocol after liver transplantation. The basic immunosuppressive regimen comprised tacrolimus (TAC) and methylprednisolone (MPL), with doses gradually being tapered off. The trough whole blood levels of TAC were maintained between 8 and $15 \mathrm{ng} / \mathrm{mL}$ in the first few postoperative weeks and between 5 and $10 \mathrm{ng} / \mathrm{mL}$ thereafter (a). Renal insufficiency (RI) group received CNI-sparing immunosuppressive regimen (CSR) consisting of TAC reduction and concomitant use of mycophenolat mofetil (MMF) (b).

2.3. Immune Monitoring by an In Vitro MLR Assay. For monitoring the immune state, an in vitro MLR assay was performed at 1, 3, 6, and 12 months after LT. Briefly, peripheral blood mononuclear cells prepared from the blood of the recipients, donors, and healthy volunteers with the same blood type as the donors (third-party control) for use as the stimulator cells were irradiated with $30 \mathrm{~Gy}$, and those obtained from the recipients for use as responder cells were labeled with $5 \mathrm{~lm}$ CFSE (Molecular Probes Inc., Eugene, OR, USA), as described previously [18]. The stimulator and responder cells were incubated for 5 days. CFSE stably stains intracellular proteins without causing toxicity, and the fluorescence intensity of each stained cell segregates equally among daughter cells during cell division, resulting in sequential halving of the cellular fluorescence intensity with every successive generation. After culturing for MLR, the harvested cells were stained with either phycoerythrin- (PE-) conjugated antihuman CD4 or PE-conjugated antihuman CD8 monoclonal antibodies and subjected to analysis by flow cytometry. All analyses were performed on a FACSCalibur flow cytometer (Becton Dickinson, Mountain View, CA, USA). T-cell proliferation was visualized by the serial-halving of the fluorescence intensity of CFSE. CD4 ${ }^{+}$and $\mathrm{CD} 8^{+}$T-cell proliferation and stimulation index were quantified using a method described previously [18].

2.4. Statistical Analysis. Quantitative variables were expressed as mean \pm standard deviation (SD) or median (range). Categorical variables were presented as values and 
TABLe 1: Patient characteristics at living donor liver transplantation.

\begin{tabular}{|c|c|c|c|}
\hline$\left(\mathrm{eGFR}\left(\mathrm{mL} / \mathrm{min} / 1.73 \mathrm{~m}^{2}\right)\right)$ & $\begin{array}{c}\text { Non-RI group }(n=41) \\
(94.8 \pm 26.9)\end{array}$ & $\begin{array}{l}\text { RI group }(n=19) \\
\quad(42.5 \pm 15.9)\end{array}$ & $P$ value \\
\hline Age at LT (years) & $49.2 \pm 11.5$ & $52.9 \pm 9.0$ & 0.23 \\
\hline Male sex- $n(\%)$ & $21(51.2)$ & $13(68.4)$ & 0.21 \\
\hline Primary diagnosis $-n(\%)$ & & & 0.63 \\
\hline $\mathrm{HBV}$ & $15(36.6)$ & $9(47.4)$ & \\
\hline Alcoholic & $8(19.5)$ & $5(26.3)$ & \\
\hline $\mathrm{AIH}$ & $4(9.8)$ & $1(5.3)$ & \\
\hline Others & $14(34.1)$ & $4(21.1)$ & \\
\hline MELD & $16.5 \pm 7.1$ & $24.7 \pm 10.7$ & $<0.01$ \\
\hline eGFR at 1 st year after LT $\left(\mathrm{mL} / \mathrm{min} / 1.73 \mathrm{~m}^{2}\right)$ & $77.2 \pm 28.2$ & $60.1 \pm 13.5$ & $<0.01$ \\
\hline eGFR $>60$ at 1 st year after $\mathrm{LT}-n(\%)$ & $26(72.2)$ & $10(58.8)$ & 0.33 \\
\hline AR within 1 st year- $n(\%)$ & $10(24.4)$ & $5(26.3)$ & 0.87 \\
\hline Bacterial infections- $n(\%)$ & $13(31.7)$ & $8(42.1)$ & 0.43 \\
\hline Fungal infections- $n(\%)$ & $4(9.8)$ & $4(21.1)$ & 0.23 \\
\hline CMV infections- $n(\%)$ & $10(24.4)$ & $7(36.8)$ & 0.32 \\
\hline
\end{tabular}

RI, renal insufficiency; LT, liver transplantation; HBV, hepatitis B virus; AIH, Autoimmune hepatitis; eGFR, estimated glomerular filtration rate; MELD, model for end-stage liver disease; AR, acute rejection; CMV, cytomegalovirus. Data are expressed as means \pm standard deviation. Difference with $P<0.05$ was considered significant.

percentages. Student's $t$-test, Mann-Whitney test, chi-square test, and Fischer's exact test were used to compare variables between the two groups. Paired $t$-tests were performed to compare continuous variables throughout the study period. The Kaplan-Meier analyses were used to compare time-toevent variables. $P$ Values $<0.05$ were considered statistically significant.

\section{Results}

The 60 patients included 34 males and 26 females; their ages ranged from 20 to 69 (median 52) years. The primary diseases in these patients included hepatitis B virus-related cirrhosis in 24 patients (of these, 18 patients had HCC), alcoholic cirrhosis in 13 patients (of these, 6 patients had HCC), autoimmune hepatitis in 5 patients (of these, 1 patient had HCC), and other diseases in 18 patients.

Before the LTs, $68 \%$ of the patients had none to mild RI (non-RI group; mean eGFR, $94.8 \pm 26.9 \mathrm{~mL} / \mathrm{min} / 1.73 \mathrm{~m}^{2}$ ) and $32 \%$ of the patients had moderate to severe RI (RI group; mean eGFR, $42.5 \pm 15.9 \mathrm{~mL} / \mathrm{min} / 1.73 \mathrm{~m}^{2}$ ). The characteristics of these patients are listed in Table 1. There was a difference in MELD score between the groups. Mean TAC trough levels during the first year after LT in the non-RI and RI groups are shown in Figure 2(a). There were differences in mean TAC trough levels during 3 months after LT between the groups. One year after the LDLTs, the mean eGFR in the non-RI group had significantly deteriorated (from $94.8 \pm$ 26.9 to $\left.77.2 \pm 28.2 \mathrm{~mL} / \mathrm{min} / 1.73 \mathrm{~m}^{2}, P<0.01\right)$. In contrast, the mean eGFR in the RI group had significantly improved after LT (from $42.5 \pm 15.9$ to $60.1 \pm 13.5 \mathrm{~mL} / \mathrm{min} / 1.73 \mathrm{~m}^{2}$, $P<0.01)$, although it was still lower than that of the non-RI group (Figure 2(b)). Notably, $53 \%$ of the patients in the RI group were completely cured of RI by 1 year after LT. None of the patients had severe RI at 1 year after LT nor required chronic hemodialysis during the observation period.

To evaluate the immune status of these patients, we employed a serial MLR assay using a CFSE-labeling technique. Lack of proliferation of both $\mathrm{CD}^{+}$and $\mathrm{CD}^{+}$T-cells in the antidonor CFSE-MLR assay indicates suppression of the antidonor response, whereas a remarkable proliferation of these $\mathrm{T}$-cells reflects a strong antidonor response. In both groups, limited $\mathrm{CD}^{+}$and $\mathrm{CD} 8^{+} \mathrm{T}$-cell proliferation was observed in the antidonor responses as compared with the anti-third-party responses through the first year. At 1 month after LT, the average of stimulation index (SI) for $\mathrm{CD}^{+}{ }^{+} \mathrm{T}$-cells in response to anti-third-party stimulation was $>2$ (the average value in healthy volunteers without any immunosuppressive treatment) that is, there was a normal response in the anti-third-party (Figures 3(a) and 3(b)). At 1 year after LT, the average of SIs for $\mathrm{CD}^{+}$and $\mathrm{CD}^{+}{ }^{+} \mathrm{T}$-cells in response to both antidonor and anti-third-party stimulation was $<2$ (Figures 3(c) and 3(d)). There were no significant differences in acute rejection rates, bacterial, fungal, or cytomegalovirus infection rates and patient survival between the groups (Table 1).

\section{Discussion}

Chronic RI is a serious complication in liver transplantation that significantly compromises patient survival and outcome. Depending on the criteria applied for a definition of chronic renal insufficiency and the duration of followup, the reported rate of chronic renal insufficiency after liver transplantation may vary from $10 \%$ to $80 \%$ [1,20-22]. CNI toxicity has been defined as one of the possible risk factors for renal insufficiency in long-term liver transplant survivors. It has been shown that exposure to CNIs within the first 6 months 


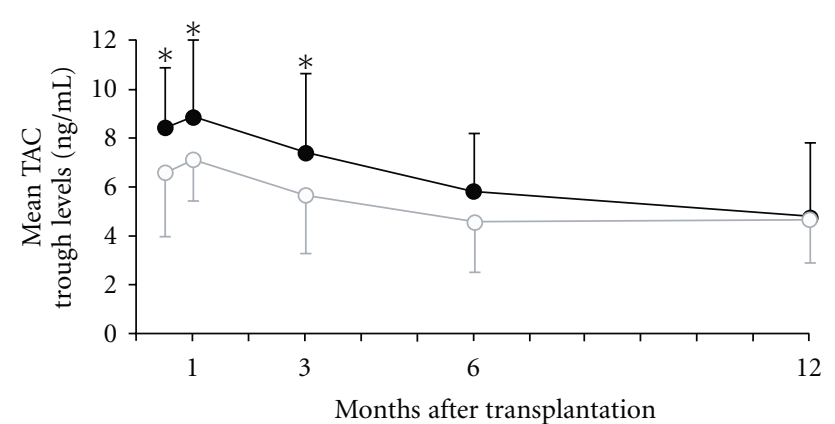

(a)

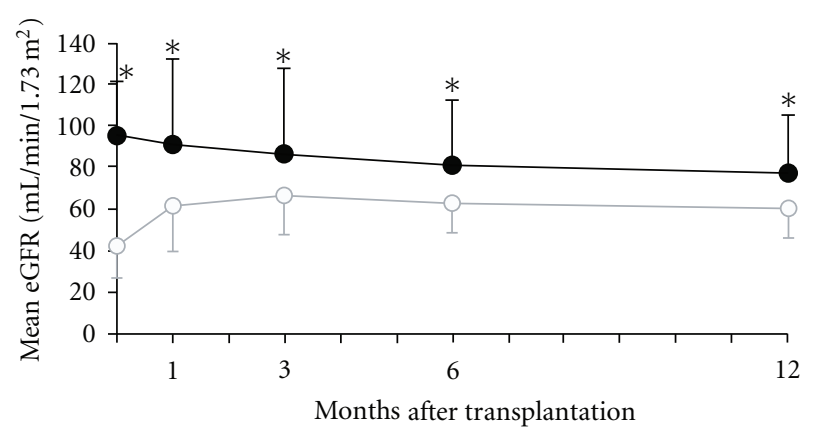

(b)

Figure 2: Kinetics of mean trough levels of tacrolimus and mean estimated glomerular filtration rate (eGFR) in the RI group and non-RI group during the first year after transplantation. (a) Mean trough levels of tacrolimus in the non-RI group (black line) and RI group (gray line). (b) Mean estimated glomerular filtration rate (eGFR) in the non-RI group (black line) and RI group (gray line). Data are median \pm SD of values. ${ }^{*} P<0.05$.

after liver transplantation represents a risk factor for renal failure [23]. The GFR at 1 year had a better correlation with later renal function than the pretransplant GFR [24]. The recognition of these facts induced interest in preventing CNI toxicity. It has also reported that the use of adjunctive MMF immediately after LT might protect against CNI nephrotoxicity, potentially without the need for dose reduction or increased risk of adverse events [25]. Therefore, current strategies to overcome CNI toxicity include reduction or withdrawal of CNIs along with switching to mTOR inhibitor or MMF-based regimens $[11,12,14,15,26-28]$. These strategies have been documented in several recent and ongoing trials to achieve an improvement in renal function in a large proportion of liver transplant patients.

In our CSR using MMF, wherein our study results agree with the results from previous studies, patients with pre-transplant renal insufficiency were associated with less impairment of renal function without an increased frequency of rejection, infection, or patient survival. In addition to this clinical evidence for the usefulness of the CSR using MMF, the present study provides immunological evidence, by analyzing the data obtained from an MLR assay, that antidonor T-cell responses were adequately suppressed in patients who received the CSR and in patients who received the conventional immunosuppressive regimen. Notably, the

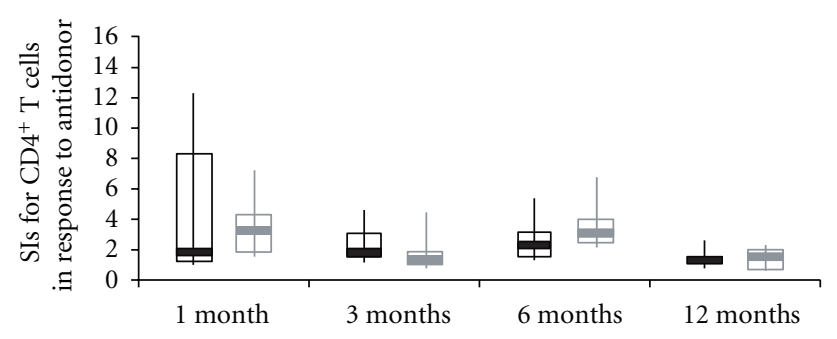

(a)

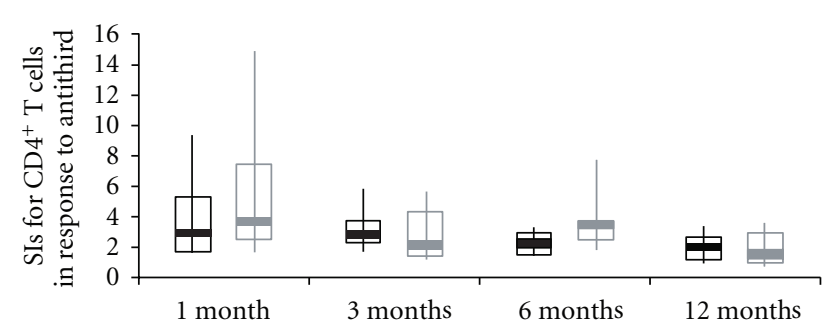

(b)

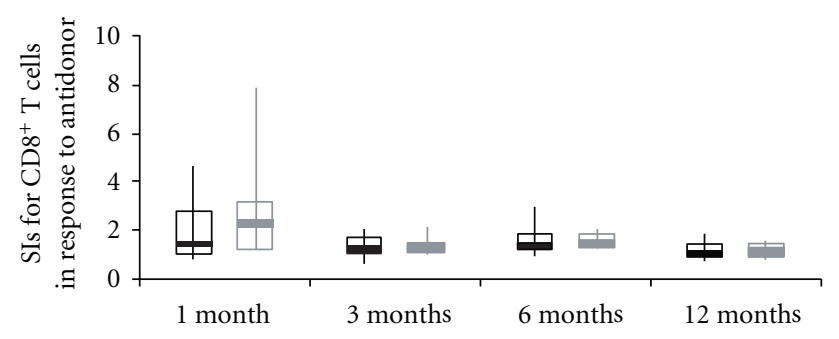

(c)

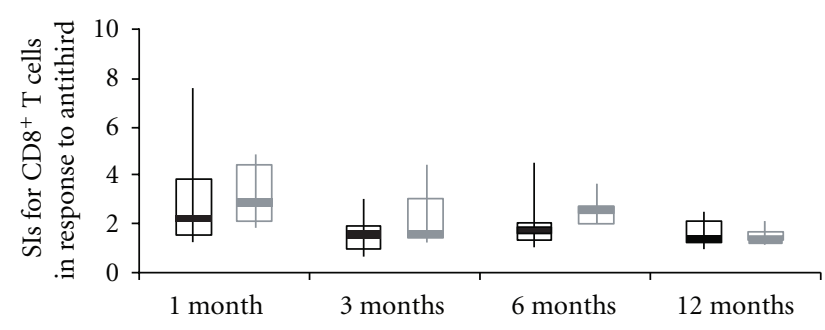

(d)

Figure 3: Kinetics of stimulation index in the RI group and nonRI group during the first year after transplantation. Stimulation index (SI) of each of the CD4 ${ }^{+} \mathrm{T}$-cell $(\mathrm{a}, \mathrm{b})$ and $\mathrm{CD} 8^{+} \mathrm{T}$-cell $(\mathrm{c}$, d) subsets in the antidonor (a, c) and anti-third-party (b, d) MLR in patients in non-RI group (black line) and RI group (gray line). $\mathrm{CD}^{+}$and $\mathrm{CD} 8^{+} \mathrm{T}$-cell proliferation and their SIs were quantified as follows. The number of division precursors was extrapolated from the number of daughter cells of each division, and the number of mitotic events in each of the $\mathrm{CD}^{+}$and $\mathrm{CD}^{+}$T-cell subsets was calculated. Using these values, the mitotic index was calculated by dividing the total number of mitotic events by the total number of precursors. The SIs of allogeneic combinations were calculated by dividing the mitotic index of a particular allogeneic combination by that of the self-control. The box plot represents the 25 th to 75th percentile, the dark line is the median, and the extended bars represent the 10th to the 90 th percentile.

individual variations of SIs of $\mathrm{CD}^{+}{ }^{+} \mathrm{T}$-cell and $\mathrm{CD} 8^{+} \mathrm{T}$ cell subsets on antidonor T-cell responses in patients who received the CSR were smaller than those in patients who 
received the conventional regimen, although the average values of both were similar. This might be explained by the possibility that the CSR comprising triple immunosuppressive drugs was equally effective in a wide variety of patients.

Several limitations of this study are present. Our sample size was relatively small without long-term followup, and single-center retrospective data are reported. Since the 2 groups of patients are not perfectly comparable as renal impairment can reduce immune responses, we could not rule out a possibility that reduced CNI, without necessarily adding MMF, may be sufficient for the treatment of these patients.

We excluded HCV positive cases and ABO-blood group incompatible cases from the study because of diverse protocol (In brief, in patients with HCV infection, methylprednisolone is not administered, which may be beneficial for preventing enhanced viral replication. Instead, basiliximab and MMF are usually administered to such patients. In ABOblood group incompatible cases, anti-CD20 monoclonal antibody is administered for eliminating temporarily B cells 2 weeks before transplantation, and simultaneously commencing administration of CNI and MMF.). Hence, the effect of CSR in RI patients with those backgrounds remains to be elucidated. Nevertheless, this first evaluation of the immune state in liver transplant patients suffering from RI received a CSR was essential before to propose an evaluation at a larger scale.

In conclusion, patients with pre-transplant RI receiving CSR under immunological monitoring using an MLR assay were associated with less impairment of renal function without an increased frequency of rejection or patient survival. Antidonor T-cell responses were adequately suppressed in these patients as well as in patients who received the conventional immunosuppressive regimen comprising a standard dose of CNI.

\section{Abbreviations}

$\begin{array}{ll}\text { AIH: } & \text { Autoimmune hepatitis } \\ \text { AR: } & \text { acute rejection } \\ \text { CFSE: } & \text { carboxyfluorescein diacetate succinimidyl ester } \\ \text { CMV: } & \text { cytomegalovirus } \\ \text { CNI: calcineurin inhibitor } & \text { CSR: } \quad \text { CNI sparing immunosuppressive regimen } \\ \text { eGFR: } & \text { estimated glomerular filtration rate } \\ \text { HBV: } & \text { hepatitis B virus } \\ \text { HCV: } & \text { hepatitis C virus } \\ \text { LT: } & \text { liver transplantation } \\ \text { MELD: } & \text { model for end-stage liver disease } \\ \text { MLR: } & \text { mixed lymphocyte reaction } \\ \text { MMF: } & \text { mycophenolate mofetil } \\ \text { mTOR: } & \text { mammalian target of rapamycin } \\ \text { MPL: } & \text { methylprednisolone } \\ \text { RI: } & \text { renal insufficiency } \\ \text { SI: } & \text { stimulation index } \\ \text { TAC: } & \text { tacrolimus. }\end{array}$

\section{References}

[1] K. P. Platz, A. R. Mueller, G. Blumhardt et al., "Nephrotoxicity following orthotopic liver transplantation: a comparison between cyclosporine and FK506," Transplantation, vol. 58, no. 2, pp. 170-178, 1994.

[2] N. C. Fisher, P. G. Nightingale, B. K. Gunson, G. W. Lipkin, and J. M. Neuberger, "Chronic renal failure following liver transplantation: a retrospective analysis," Transplantation, vol. 66, no. 1, pp. 59-66, 1998.

[3] T. A. Gonwa, G. B. Klintmalm, M. Levy, L. S. Jennings, R. M. Goldstein, and B. S. Husberg, "Impact of pretransplant renal function on survival after liver transplantation," Transplantation, vol. 59, no. 3, pp. 361-365, 1995.

[4] S. Nair, S. Verma, and P. J. Thuluvath, "Pretransplant renal function predicts survival in patients undergoing orthotopic liver transplantation," Hepatology, vol. 35, no. 5, pp. 11791185, 2002.

[5] B. D. Myers, "Cyclosporine nephrotoxicity," Kidney International, vol. 30, pp. 964-974, 1986.

[6] J. B. Puschett, A. Greenberg, J. Holley, and J. McCauley, "The spectrum of ciclosporin nephrotoxicity," American Journal of Nephrology, vol. 10, no. 4, pp. 296-309, 1990.

[7] M. K. Porayko, T. A. Gonwa, G. B. Klintmalm, and R. H. Wiesner, "Comparing nephrotoxicity of FK 506 and cyclosporine regimens after liver transplantation: preliminary results from US multicenter trial," Transplantation Proceedings, vol. 27, no. 1, pp. 1114-1116, 1995.

[8] A. O. Ojo, P. J. Held, F. K. Port et al., "Chronic renal failure after transplantation of a nonrenal organ," The New England Journal of Medicine, vol. 349, no. 10, pp. 931-940, 2003.

[9] T. A. Gonwa, M. L. Mai, L. B. Melton et al., "End-stage renal disease (ESRD) after orthotopic liver transplantation (OLTX) using calcineurin-based immunotherapy: risk of development and treatment," Transplantation, vol. 72, no. 12, pp. 19341939, 2001.

[10] A. Pawarode, D. M. Fine, and P. J. Thuluvath, "Independent risk factors and natural history of renal dysfunction in liver transplant recipients," Liver Transplantation, vol. 9, no. 7, pp. 741-747, 2003.

[11] S. A. Farkas, A. A. Schnitzbauer, G. Kirchner, A. Obed, B. Banas, and H. J. Schlitt, "Calcineurin inhibitor minimization protocols in liver transplantation," Transplant International, vol. 22, no. 1, pp. 49-60, 2009.

[12] H. J. Schlitt, A. Barkmann, K. H. W. Böker et al., "Replacement of calcineurin inhibitors with mycophenolate mofetil in livertransplant patients with renal dysfunction: a randomised controlled study," The Lancet, vol. 357, no. 9256, pp. 587-591, 2001.

[13] S. Beckebaum, V. Cicinnati, E. Brokalaki, A. Frilling, G. Gerken, and C. E. Broelsch, "CNI-sparing regimens within the liver transplant setting: experiences of a single center," Clinical Transplants, pp. 215-220, 2004.

[14] C. L. Liu, S. T. Fan, C. M. Lo et al., "Interleukin-2 receptor antibody (basiliximab) for immunosuppressive induction therapy after liver transplantation: a protocol with early elimination of steroids and reduction of tacrolimus dosage," Liver Transplantation, vol. 10, no. 6, pp. 728-733, 2004.

[15] G. P. Pageaux, L. Rostaing, Y. Calmus et al., "Mycophenolate mofetil in combination with reduction of calcineurin inhibitors for chronic renal dysfunction after liver transplantation," Liver Transplantation, vol. 12, no. 12, pp. 1755-1760, 2006. 
[16] S. M. Flechner, J. Kobashigawa, and G. Klintmalm, "Calcineurin inhibitor-sparing regimens in solid organ transplantation: focus on improving renal function and nephrotoxicity," Clinical Transplantation, vol. 22, no. 1, pp. 1-15, 2008.

[17] S. Karie-Guigues, N. Janus, F. Saliba et al., "Long-term renal function in liver transplant recipients and impact of immunosuppressive regimens (calcineurin inhibitors alone or in combination with mycophenolate mofetil): The TRY study," Liver Transplantation, vol. 15, no. 9, pp. 1083-1091, 2009.

[18] Y. Tanaka, H. Ohdan, T. Onoe et al., "Low incidence of acute rejection after living-donor liver transplantation: immunologic analyses by mixed lymphocyte reaction using a carboxyflourescein diacetate succinimidyl ester labeling technique," Transplantation, vol. 79, no. 9, pp. 1262-1267, 2005.

[19] S. Matsuo, E. Imai, M. Horio et al., "Revised Equations for Estimated GFR From Serum Creatinine in Japan," American Journal of Kidney Diseases, vol. 53, no. 6, pp. 982-992, 2009.

[20] J. McCauley, D. H. Van Thiel, T. E. Starzl, and J. B. Puschett, "Acute and chronic renal failure in liver transplantation," Nephron, vol. 55, no. 2, pp. 121-128, 1990.

[21] A. M. De Mattos, A. J. Olyaei, and W. M. Bennett, "Nephrotoxicity of immunosuppressive drugs: long-term consequences and challenges for the future," American Journal of Kidney Diseases, vol. 35, no. 2, pp. 333-346, 2000.

[22] A. J. Olyaei, A. M. De Mattos, and W. M. Bennett, "Nephrotoxicity of immunosuppressive drugs: new insight and preventive strategies," Current Opinion in Critical Care, vol. 7, no. 6, pp. 384-389, 2001.

[23] A. Wilkinson and P. T. Pham, "Kidney dysfunction in the recipients of liver transplants," Liver Transplantation, vol. 11, no. 11, pp. S47-S51, 2005.

[24] F. Åberg, A. M. Koivusalo, K. Höckerstedt, and H. Isoniemi, "Renal dysfunction in liver transplant patients: comparing patients transplanted for liver tumor or acute or chronic disease," Transplant International, vol. 20, no. 7, pp. 591-599, 2007.

[25] S. Haywood, M. Abecassis, and J. Levitsky, "The renal benefit of mycophenolate mofetil after liver transplantation," Clinical Transplantation, vol. 25, no. 1, pp. E88-E95, 2011.

[26] V. Schmitz, S. Laudi, F. Moeckel et al., "Chronic renal dysfunction following liver transplantation," Clinical Transplantation, vol. 22, no. 3, pp. 333-340, 2008.

[27] G. Orlando, L. Baiocchi, A. Cardillo et al., "Switch to 1.5 grams MMF monotherapy for CNI-related toxicity in liver transplantation is safe and improves renal function, dyslipidemia, and hypertension," Liver Transplantation, vol. 13, no. 1, pp. 46-54, 2007.

[28] G. S. Jensen, A. Wiseman, and J. F. Trotter, "Sirolimus conversion for renal preservation in liver transplantation: not so fast," Liver Transplantation, vol. 14, no. 5, pp. 601-603, 2008. 


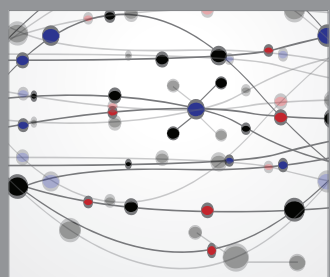

The Scientific World Journal
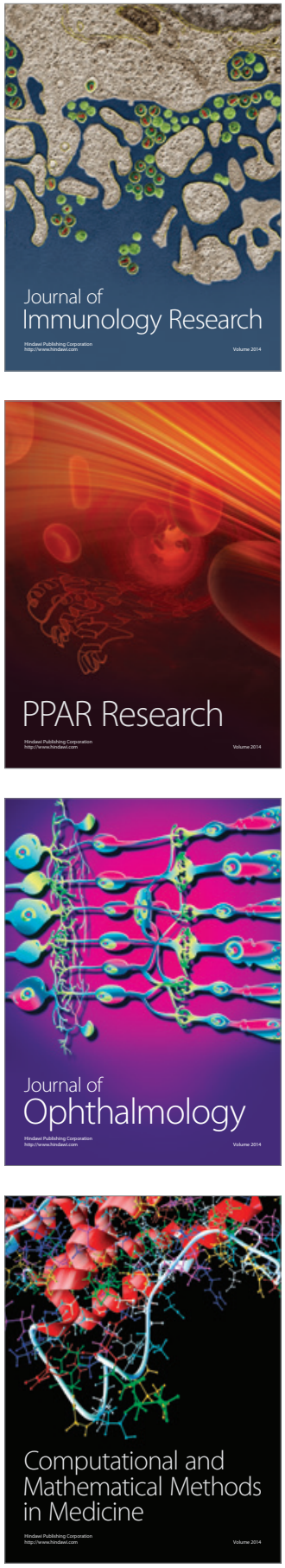

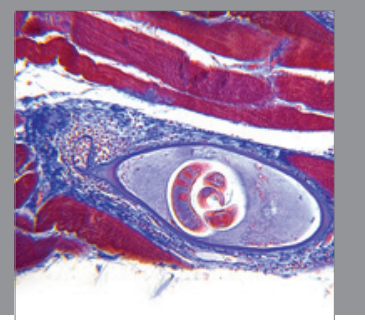

Gastroenterology

Research and Practice
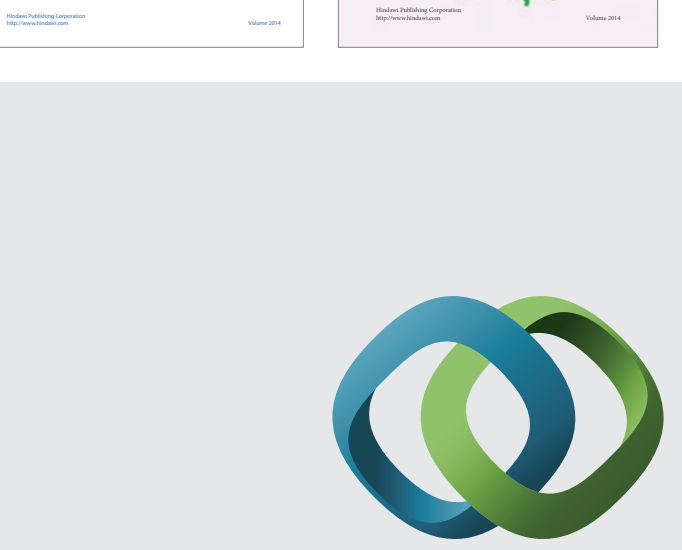

\section{Hindawi}

Submit your manuscripts at

http://www.hindawi.com
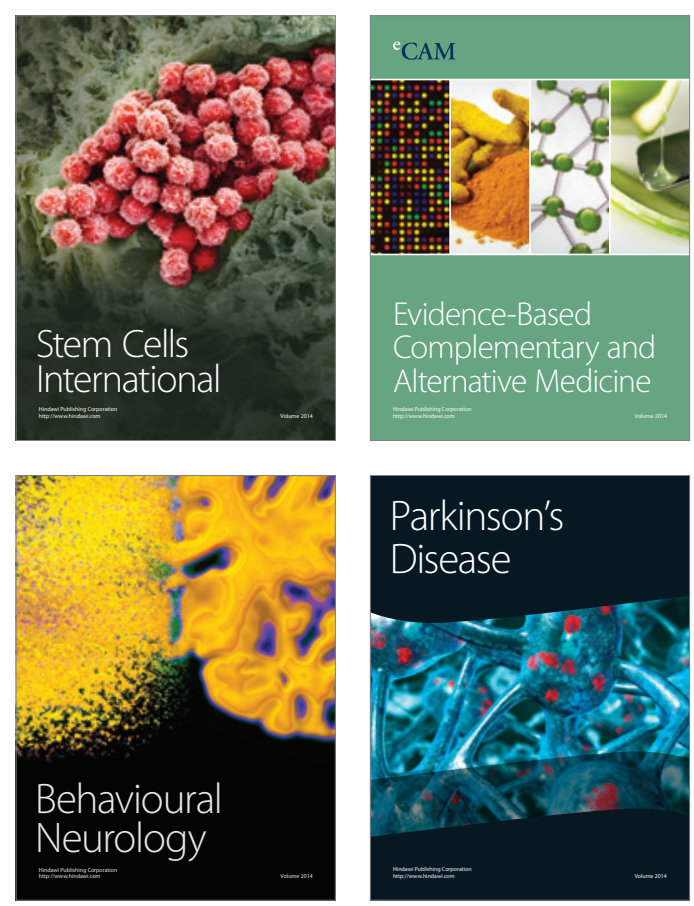

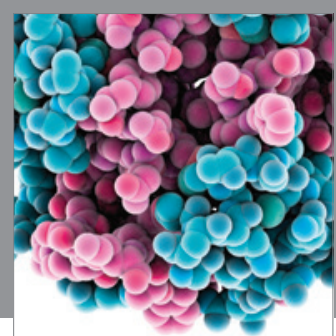

Journal of
Diabetes Research

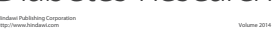

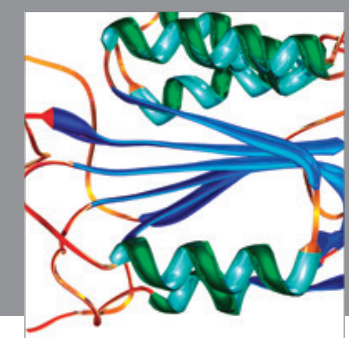

Disease Markers
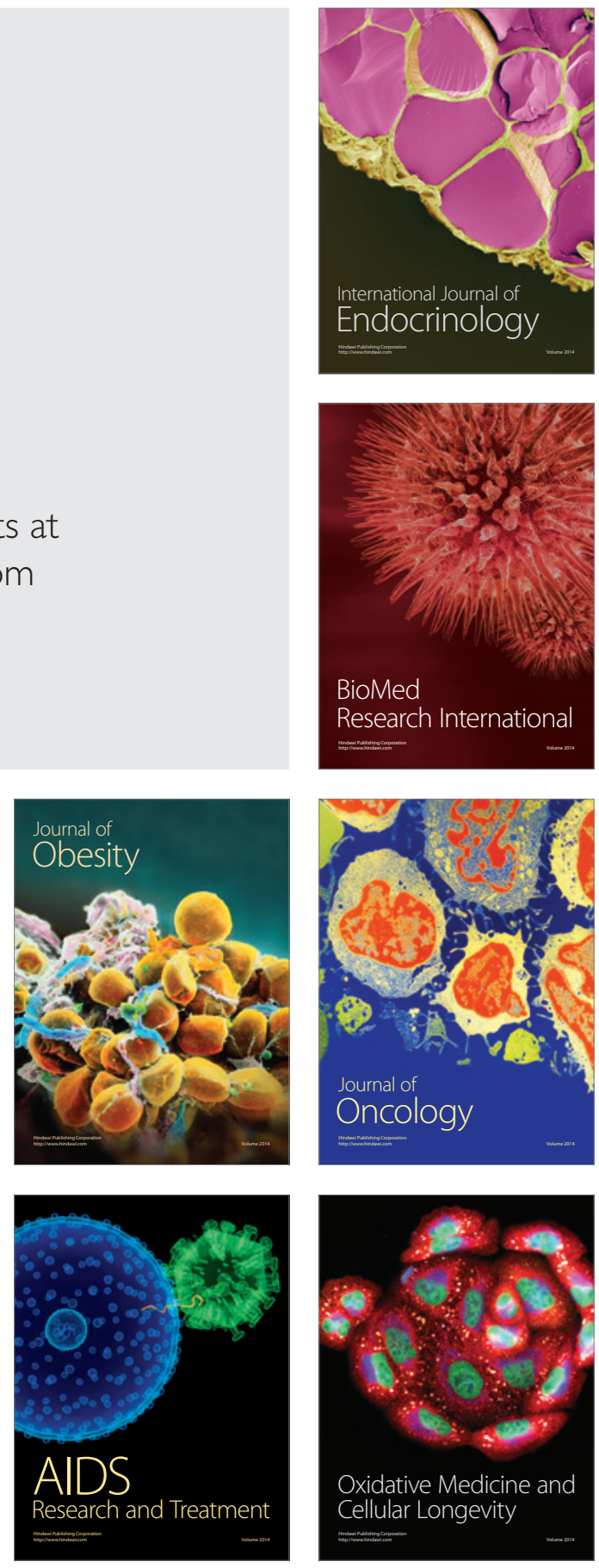